\title{
Brumadinho Dam InSAR study: analysis of TerraSAR-X, COSMO-SkyMed and Sentinel-1 images preceding the collapse
}

D Holden 3vGeomatics Inc., Canada

S Donegan 3vGeomatics Inc., Canada

A Pon 3vGeomatics Inc., Canada

\begin{abstract}
The catastrophic failure of Dam I at the Córrego do Feijão iron ore mine near Brumadinho, Brazil has brought significant attention to the range of monitoring techniques available for similar sites, including satellite Interferometric Synthetic Aperture Radar (InSAR). Satellite InSAR is a remote sensing technique that uses satellite imagery to detect millimetre scale displacements. This paper presents InSAR results covering the Brumadinho site, for the time period leading up to the dam collapse, using both high and low resolution imagery from four sets of satellite synthetic aperture radar (SAR) data. The goal of this study is to provide a set of results that may help to improve the understanding of the mechanisms behind the collapse and to understand if there was a role that InSAR could have played in detecting any anomalous displacement signals before the collapse.
\end{abstract}

Four sets of satellite SAR images are available and have been analysed in this study. These include two from the Sentinel-1 (S1) satellite constellation, which have a lower resolution $(20 \mathrm{~m})$, and two from the higher resolution ( $3 \mathrm{~m}$ ) TerraSAR-X (TSX) and COSMO-SkyMed (CSK) satellite constellations. The high resolution CSK and TSX measurements also provide a much greater level of detail on the dam that can be used to distinguish local trends.

Some subtle signals are observed on the lower portion of the dam wall in the year leading up to the collapse, however, these are not statistically significant based solely on the level of noise present in the InSAR results. At the top of the wall and inside of the enclosure, significant signal is present, as expected for a structure of this type.

Keywords: InSAR, Brumadinho, tailings, dam, failure, collapse, Córrego do Feijão

\section{Introduction}

Dam I at Vale's Córrego de Feijão iron ore mine near Brumadinho, Brazil, was a tailings dam with a height of $86 \mathrm{~m}$ and a crest length of $720 \mathrm{~m}$ (Vale S.A. (Vale) 2019a). The dam was constructed as an upstream tailings dam. On 25 January 2019, the dam catastrophically failed, resulting in the deaths of at least 248 people and the release of 12 million cubic metres of tailings (Vale 2019b). This tragedy has justifiably generated a large focus onto what could have been done to prevent it and similar events in the future. This study is aimed at understanding what displacement on and around the dam was observable leading up to the collapse using satellite Interferometric Synthetic Aperture Radar (InSAR). The goal is to contribute to the understanding of the failure itself as well as to provide insight on the applicability of InSAR to detecting similar failure mechanisms at other sites.

Satellite InSAR is a remote sensing technique used primarily for measuring ground displacement and has wide applications in industries including mining, oil and gas recovery and infrastructure monitoring (Taylor et al. 2016; Rabus et al. 2004; 3v Geomatics Inc. (3vG) 2013). InSAR can detect ground displacement on the order of millimetres or lower in ideal circumstances (3vG 2013). This precision, coupled with a high spatial density 
of measurements and completely remote investigation, makes InSAR a valuable tool for monitoring infrastructure such as tailings dams. In various other prior mining collapses, there have been detectable InSAR precursor signals (e.g. Williams et al. 2019; Thomas et al. 2019).

A number of sets of SAR imagery are available over the Dam I site and for this study, four datasets are analysed independently. Two of these datasets have high resolution $(3 \mathrm{~m}$ ) imagery from the TerraSAR-X (TSX) and COSMO-SkyMed (CSK) satellites, while the other two sets have low resolution $(20 \mathrm{~m})$ imagery from the Sentinel-1 (S1) constellation made available by the European Space Agency (ESA). High resolution SAR imagery has been acquired in order to provide the most detailed measurements over the site, while the two sets of lower resolution images allow any observed signals to be cross-validated. For each dataset, displacement time series have been derived and signal-to-noise ratios calculated in order to understand if any measured signals register as 'significant' before the collapse.

In this paper, Section 2 describes in more detail the basis of InSAR monitoring while Section 3 describes the datasets used for this project, and more specifics of the processing chain used. In Section 4, the results of the analysis are given with an emphasis on presenting both the derived displacement time series and an associated signal-to-noise ratio to characterise the significance of any signal. Finally, the main findings of this study are reiterated in Section 5 .

\section{Interferometric synthetic aperture radar}

In satellite InSAR, radio pulses are emitted from an orbiting satellite, reflected off the ground, and then measured again by the same satellite. The difference in the phase of the reflected signal between successive orbital passes is used to derive any ground displacement that occurred between the two observations. By using the phase of the reflected signal, displacement that is just a small fraction of the wavelength of the emitted radio wave can be detected, allowing for incredibly precise measurements to be made by satellites orbiting approximately $800 \mathrm{~km}$ above a site. The emitted wavelength is approximately $3 \mathrm{~cm}$ for TerraSAR-X \& COSMO-SkyMed and $5.6 \mathrm{~cm}$ for Sentinel-1. One limitation of InSAR is that changes to the ground surface significantly greater in scale than the wavelength of the radio pulses, such as produced by normal mining activity, can destroy the measurements. Vegetation also poses a challenge as the signals from these areas are continuously changing between images, similar to ongoing mining surface disturbances.

An image made from the phase differences between two different observations is referred to as an interferogram. Included in interferograms are desirable signals, such as the ground displacement, and also 'noise' signals, such as signals introduced by atmospheric contamination and signals relating to errors in the elevation models used in the processing. The displacement signal is the component of the true ground displacement that occurred in the direction of the satellite line of sight (LOS), while the atmospheric signals are contributed to by the passage of the radar signal through different distances, humidity and air pressure at the times when each image used to form the interferogram was acquired. Figure 1 shows an example interferogram and SAR amplitude image alongside optical imagery over Dam I. 


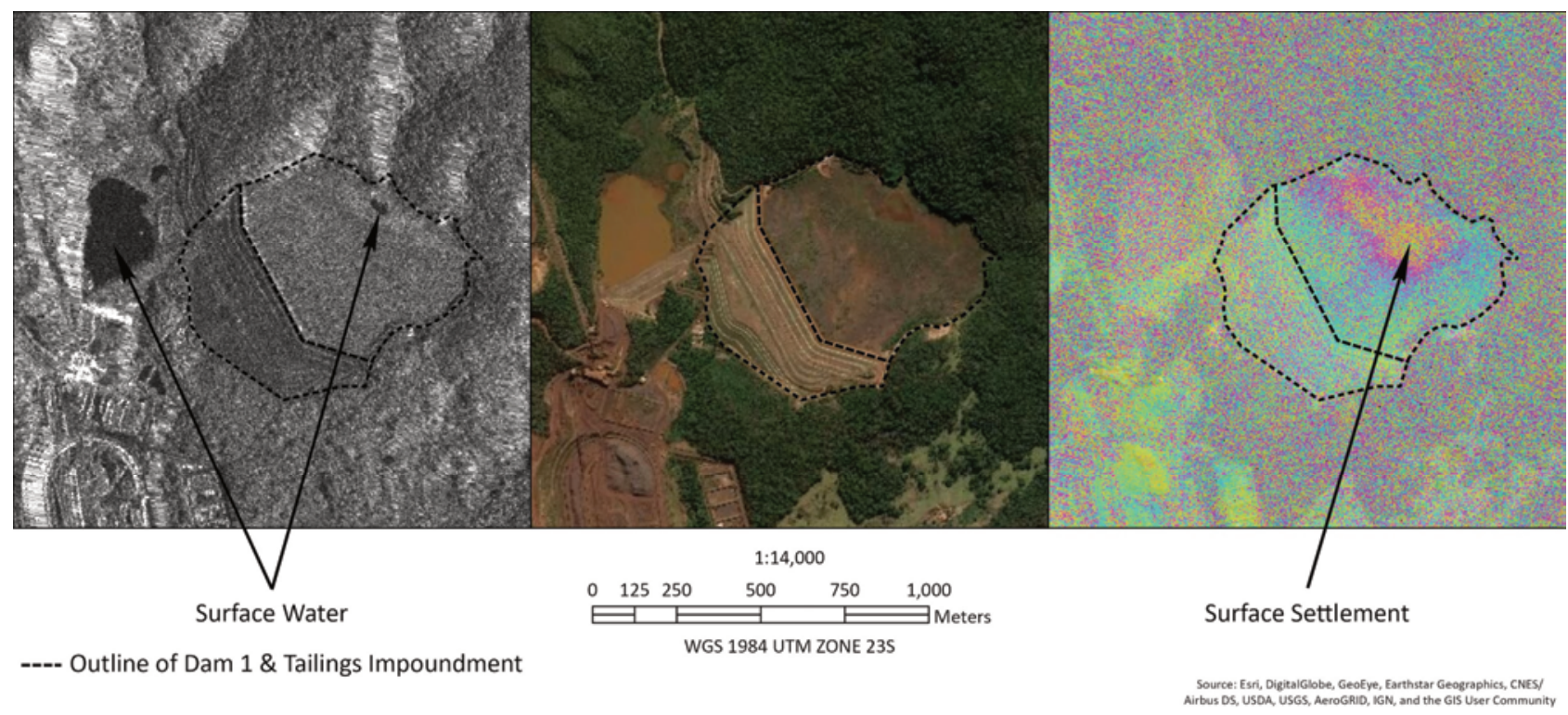

Figure 1 Optical imagery from Google Earth acquired on 22 July 2018 (centre), alongside the amplitude from a COSMO-SkyMed (CSK) synthetic aperture radar (SAR) image acquired 8 January 2019 (left) and an interferogram made between CSK SAR images acquired 27 December 2018 and 8 January 2019 (right) over Dam I. The interferogram has already been coregistered, corrected for atmospheric contamination and filtered. Inside the impoundment there is high signal quality, the dam shows reasonable quality, and the speckled 'noise' regions are mostly due to vegetation. The area of magenta and yellow within the tailings impoundment likely represents approximately $1 \mathrm{~cm}$ of settlement during the period covered by the interferogram. The darkest areas of the amplitude image mostly correspond to water bodies and ponds

Achieving a high quality interferogram requires precise alignment of the images. For satellite InSAR, due to the fixed orbits of the satellite, this means that the satellite needs to return to the position of the original image to acquire the next image. This period, called the satellite revisit, differs between most satellites, but for current commercial SAR satellites is typically between 11 to 24 days. Some satellites are also part of a constellation, all in very similar orbits, which allows them to have shorter effective revisits. That the measurement update rate is on the order of days, rather than minutes, as can be achieved with ground instrumentation, is a key limitation to be understood. Precursor ground displacement prior to a failure can only be reliably identified if it occurs over a time period greater than the revisit rate of the satellite imagery used. Such precursor movement has been seen at other tailings dams before a failure has occurred (Thomas et al. 2019).

The measurement perspective (LOS direction) offered by the satellite imagery is also unique to satellite (or airborne) InSAR. The imagery is acquired mostly from the right-hand side relative to the satellite's orbit direction at an angle between $15^{\circ}-60^{\circ}$ from vertical (European Space Agency Earth Observation Portal (ESA) 2002a, 2002b). InSAR satellites typically are placed in polar orbits, such that they travel in either south-tonorth (ascending) or north-to-south (descending) trajectories when acquiring images over a site. Taking into account these directions and some other geometric effects associated with SAR imaging, such as layover and shadow, the result is that an interferogram formed by ascending images has good sensitivity to vertical and downslope displacement on east facing hillsides, while interferograms formed by descending images have better sensitivity to vertical and downslope displacement on west facing hillsides. 


\section{Approach}

\subsection{Data collection}

The initial goal of this investigation was to determine if any precursor signals could have been detected before the collapse of Dam I. The approach taken has been to independently process four sets of imagery that are available, starting immediately prior to the collapse and extending back more than three years prior. The four image sets include a high resolution, ascending TSX set; a high resolution, descending CSK set; and two independent low resolution, descending S1 sets. Figure 2 plots the dates of the image acquisitions for each of the image sets that are also described in Table 1.

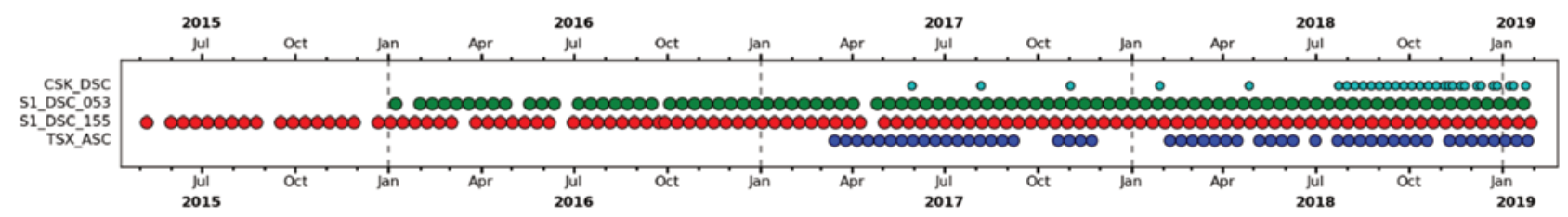

Figure 2 Spread of synthetic aperture radar (SAR) imagery used in this study. The size of the circles is proportional to the most common revisit interval between the images from each image set ( $\mathrm{S} 1=12$ days, $\mathrm{CSK}=8$ days, $\mathrm{TSX}=11$ days $)$

Table 1 Properties of the four sets of satellite synthetic aperture radar (SAR) imagery used in this study

\begin{tabular}{lcccc}
\hline Satellite & $\begin{array}{c}\text { Radar } \\
\text { wavelength } \\
(\mathbf{c m})\end{array}$ & $\begin{array}{c}\text { Ground } \\
\text { resolution } \\
(\mathbf{m})\end{array}$ & $\begin{array}{c}\text { Revisit } \\
\text { period } \\
\text { (days) }\end{array}$ & $\begin{array}{c}\text { Look } \\
\text { direction }\end{array}$ \\
\hline TerraSAR-X & 3 & 4 & 11 & Asc \\
COSMO-SkyMed & 3 & 4 & $1-8^{*}$ & Dsc \\
Sentinel-1 (track 53) & 5.6 & 20 & 12 & Dsc \\
Sentinel-1 (track 155) & 5.6 & 20 & 12 & Dsc \\
\hline
\end{tabular}

*COSMO-SkyMed is a constellation of four unevenly spaced satellites, such that the revisit period between successive satellites varies between 1 and 8 days. For Dam I, no images were available with repeat intervals less than 4 days.

The 30 high resolution CSK images that have been used in this study were selected from a larger set of archive images. The images were selected to provide the shortest revisit period leading up to the collapse while still including some coverage over a longer time period.

\subsection{InSAR processing chain}

Each set of imagery has been processed using equivalent processing chains with only small changes made to accommodate the differences in the data types and resolutions. The processing chain used for this study is described in Figure 3 and includes steps to perform the initial alignment of the SAR images and elevation information (1), account for atmospheric contamination (2) and to improve data quality (filtering) (3). There are also steps to convert the wrapped phase, which is the initial measurement, to an absolute displacement measurement (4). Errors in the initial elevation model are corrected and LOS displacement time series are generated (5). From these results the average displacement rate for the year prior to the collapse is calculated for each image set (6). In addition, a signal-to-noise ratio (SNR) has been calculated for each set of results (6). This provides an estimate of the significance of the signals that are being measured in the context of the noise floor of the data. The aim of this metric is to understand if any displacement would have been 'detected' leading up to the failure. All the results are geocoded to allow for easy comparison between the different data stacks (7). 


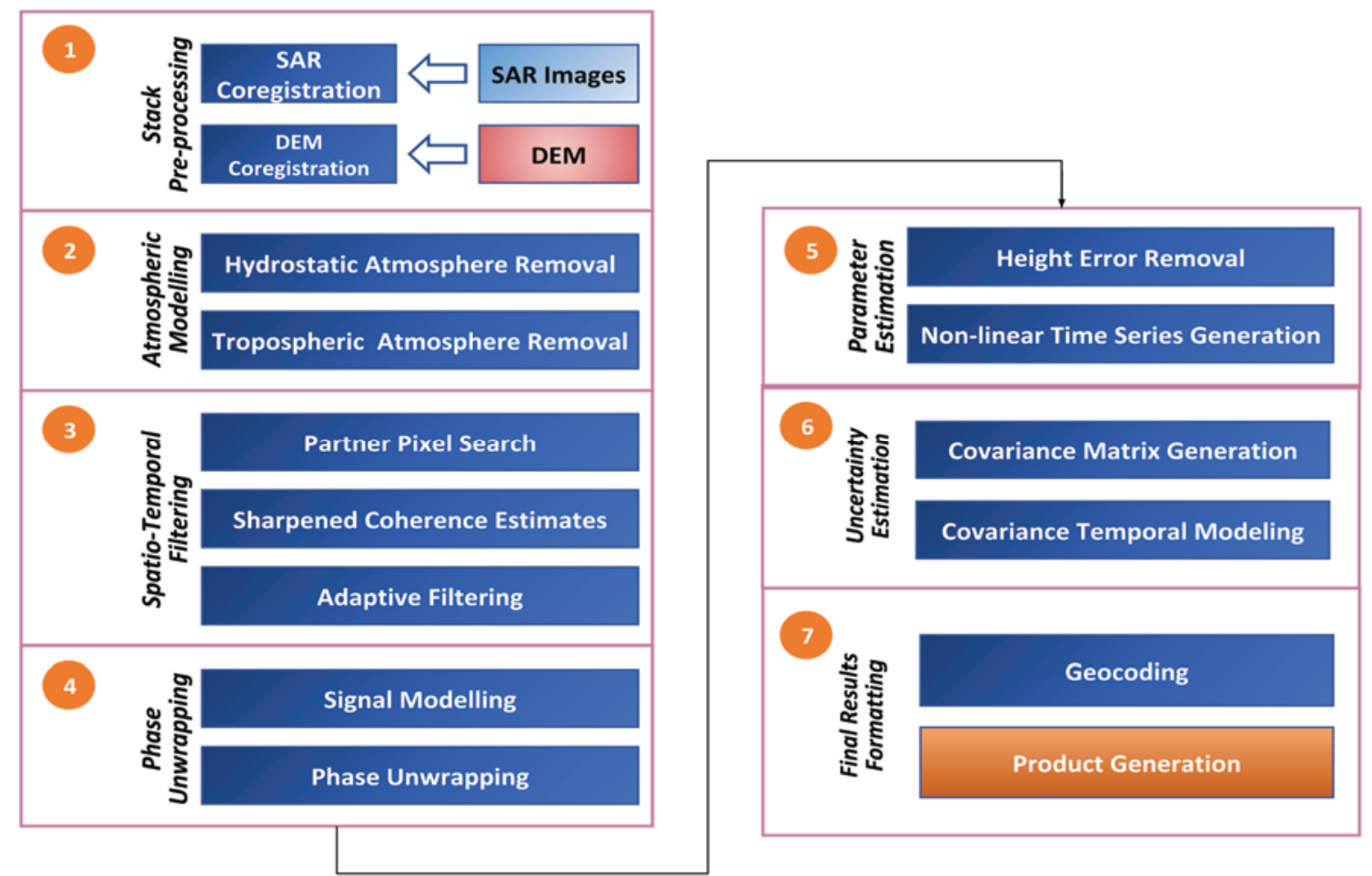

Figure 3 InSAR processing chain used for the study

The error estimates vary over time and spatially within a single image and are derived from a two component model. The first component captures the scale of the signal present in each interferogram that is due to remnant atmospheric effects. These are physically real and spatially smooth signals, but as they are only contaminants they are described with a covariance matrix. This contains the atmospheric variance for each individual data point as well as the covariance between any interferograms that share images (and therefore also share specific atmospheric conditions). The second component of the model captures errors due to changing surface conditions. These can be due to vegetation, rain, surface disturbances, snow or any other process that can change the state of the radar targets between data acquisitions. These two covariance matrices are independent and can be combined to create a unique covariance matrix that describes the uncertainties in the data for each point on the ground.

At the completion of the processing chain there is a set of measurements derived from each set of imagery that is referenced to the first date of each. There are also gaps in the results where measurements are missing due to vegetation or ground activity. From these results the total cumulative displacement can be calculated for any time period, and an average displacement rate calculated by dividing the total cumulative displacement by the time period. Combining this displacement rate with the covariance matrix yields a SNR that quantifies the significance of the detected displacement. A time series plot of each point can also be generated showing the cumulative displacement over time or the velocity trends.

\section{$4 \quad$ Results}

\subsection{Interferograms prior to collapse}

At the start of the analysis the individual interferograms made from successive image acquisitions were examined manually by operators with extensive experience evaluating InSAR results. The outcome of this qualitative investigation was that no clear, distinct sign indicating the impending collapse of the dam was seen in the data. The interferograms obtained immediately prior to the collapse did not appear significantly different from those earlier in the dataset. Based on this analysis, InSAR monitoring of the dam that relied on human interpretation would not have been able to provide a clear warning regarding the impending collapse of the dam. 


\subsection{Average rates}

Figures 4 and 5 show the calculated average displacement rate for the year before the failure of Dam I. A one year rate was selected as a compromise between having a long enough period to suppress the influence of stochastic noise in the rates while having the period short enough that any ongoing precursor displacement signal is not lost to long periods of stability before the collapse. Figure 6 shows the cumulative rate over the full-time range of the two Sentinel datasets, approximately four years, to highlight long-term displacement trends. Table 2 lists the date ranges used in the longer and shorter-term fits that are presented in these results.

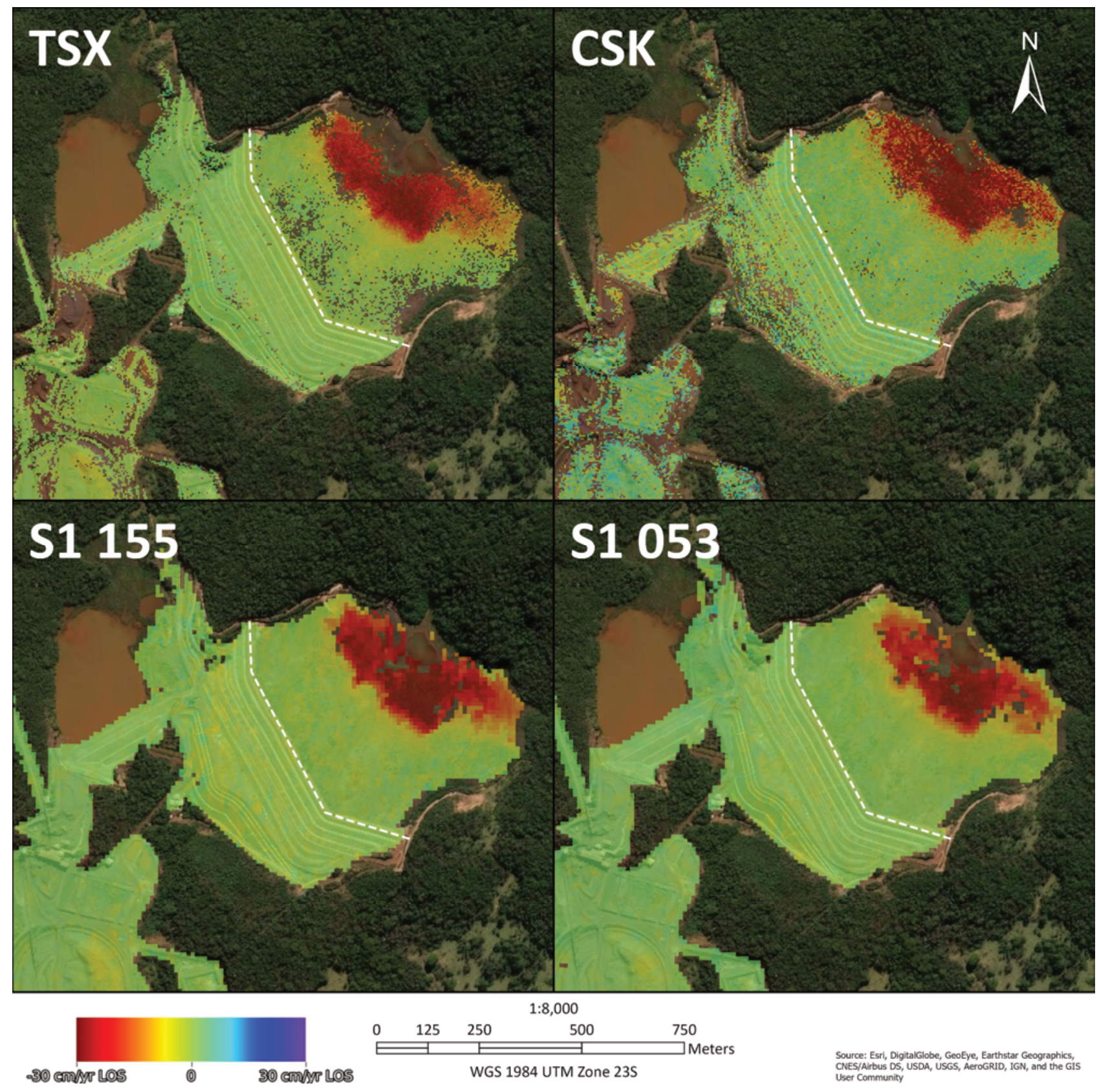

Figure 4 1-year average line of sight displacement rates over Dam I, scaled to $30 \mathrm{~cm}$ p.a., based on ascending TerraSAR-X images (top left), descending CSK images (top right), descending Sentinel-1 (track 053) images (lower right), and descending Sentinel-1 (track 155) images (lower left). The background is the pre-failure optical Esri basemap. The white dashed line denotes the location of the top of the dam 


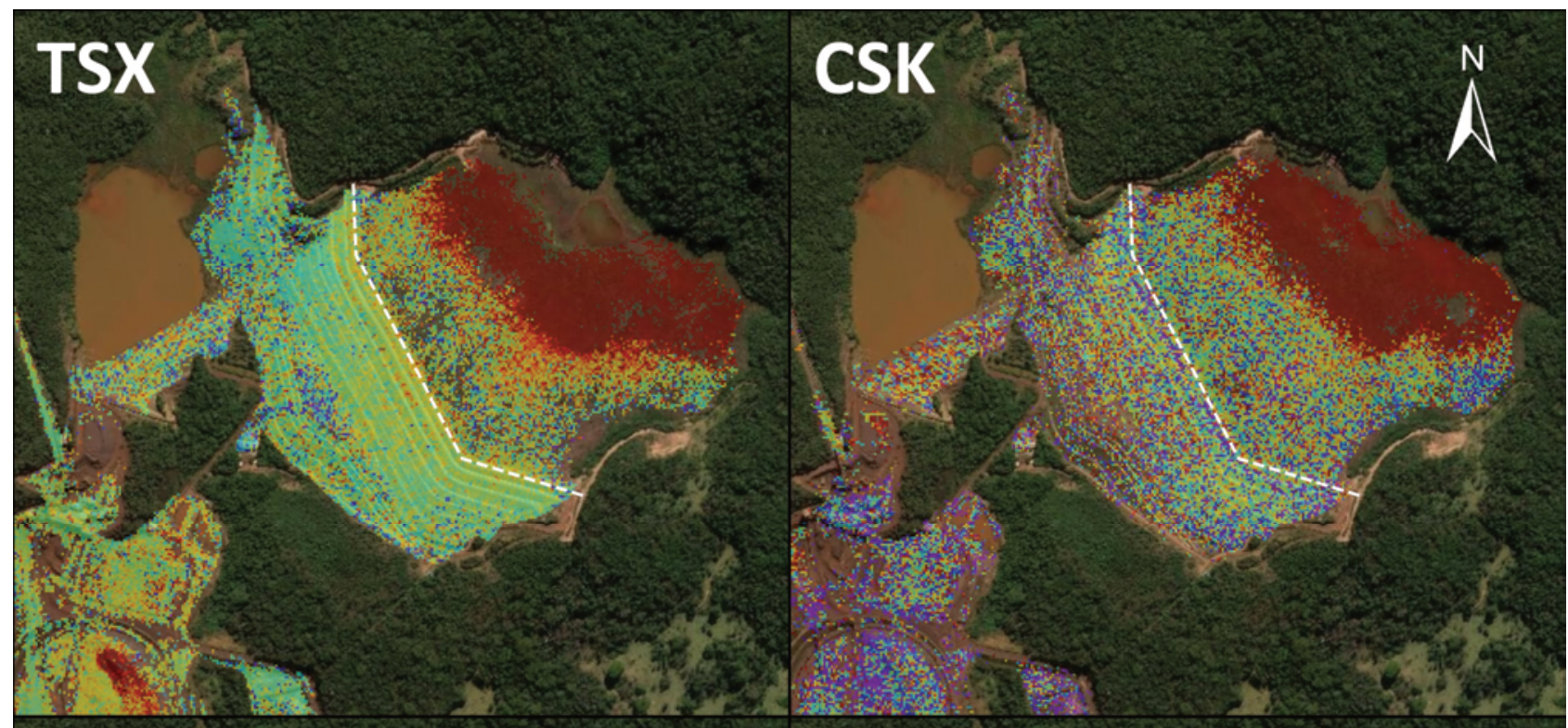

\section{S1 155}
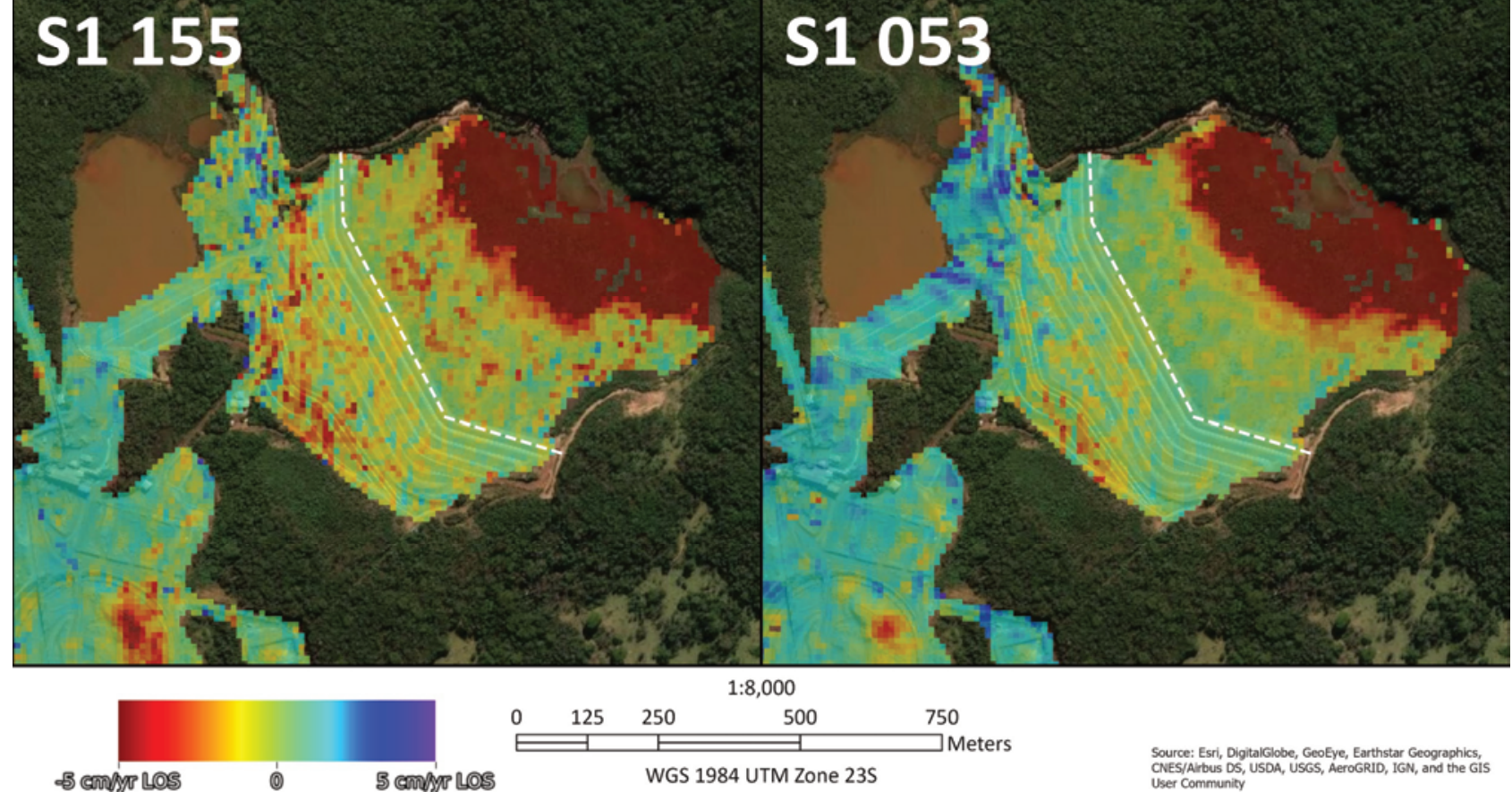

Source: Esri, DigitalGlobe, GeoEye, Earthstar Geographics,
CNES/Airbus DS, USDA, USGS, AeroGRID, IGN, and the GIS CNESSArbus DS,
User Community

Figure 5 1-year average line of sight displacement rates over Dam I, scaled to $5 \mathrm{~cm}$ p.a., based on ascending TerraSAR-X images (top left), descending CSK images (top right), descending Sentinel-1 (track 053) images (lower right), and descending Sentinel-1 (track 155) images (lower left). The background is the pre-failure optical Esri basemap. The white dashed line denotes the location of the top of the dam 


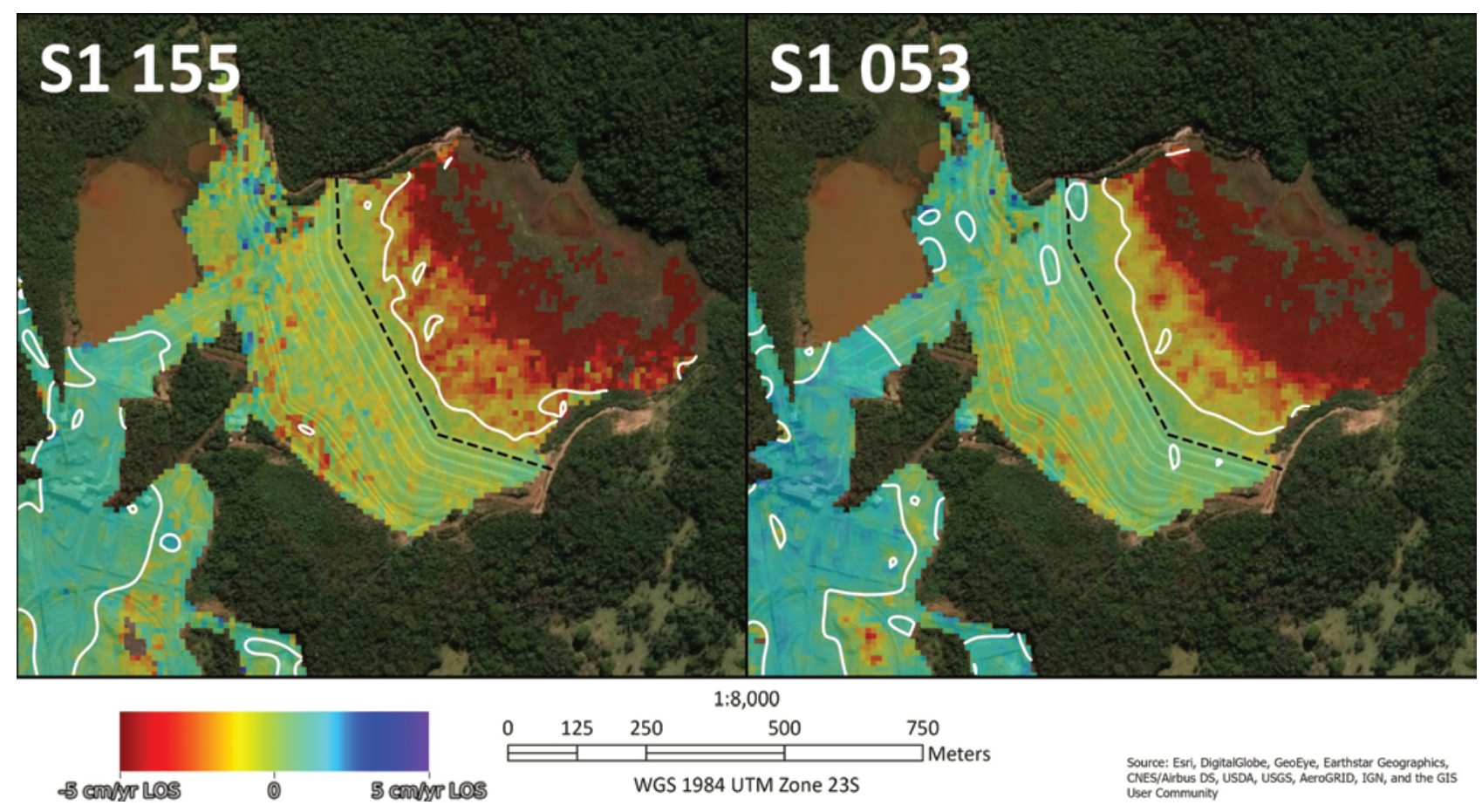

Figure 6 4-year average line of sight displacement rates over Dam I, scaled to $5 \mathrm{~cm}$ p.a., based on descending Sentinel-1 (track 053) images (right) and descending Sentinel-1 (track 155) images (left). The background is the pre-failure optical Esri basemap. The black dashed line denotes the location of the top of the dam. Contour lines surrounding areas of greater than 3.0 signalto-noise ratio are in white

Table 2 Date ranges of the synthetic aperture radar (SAR) images used to make Figures 5-8

\begin{tabular}{lll}
\hline Satellite & $\begin{array}{l}\text { Figures 4, 5, 7 } \\
\text { (1 year) }\end{array}$ & $\begin{array}{l}\text { Figure 6 } \\
\text { (4 years) }\end{array}$ \\
\hline TerraSAR-X & $\begin{array}{l}\text { 2 February 2018 to } \\
\text { 15 January 2019 }\end{array}$ & N/A \\
29 January 2018 to & N/A \\
COSMO-SkyMed & $\begin{array}{l}\text { 24 January 2019 } \\
\text { 27 January 2018 to }\end{array}$ & 1 February 2016 to \\
Sentinel-1 (track 53) & $\begin{array}{l}\text { 22 January 2019 } \\
\text { 22 January 2019 }\end{array}$ & $\begin{array}{l}\text { 2 January 2018 to } \\
\text { 8 May 2015 to } \\
\text { Sentinel-1 (track 155) }\end{array}$ \\
& 17 January 2019 & 17 January 2019 \\
\hline
\end{tabular}

Figure 4 is scaled at $30 \mathrm{~cm}$ p.a. to visualise any structure in the displacement pattern at the back of the tailing material. Positive and negative values indicate displacement towards and away from the satellite LOS, respectively. To reveal any subtle displacement occurring on the dam face, Figures 5 and 6 are scaled to a much lower value of $5 \mathrm{~cm}$ p.a.

As discussed in Section 3.2, the SNR metric is an approach for identifying the statistical significance of the signals measured in the four datasets. Figure 7 shows the SNR values for the rates shown in Figures 4 and 5. Also included is a white contour line drawn at an SNR of 3.0. Quantitatively, three SNR contours indicate where there is a $0.26 \%$ chance that a signal as large as is observed could be produced by noise alone. Three sigma contours, based on the full four year S1 datasets, are also overplotted on Figure 6. 


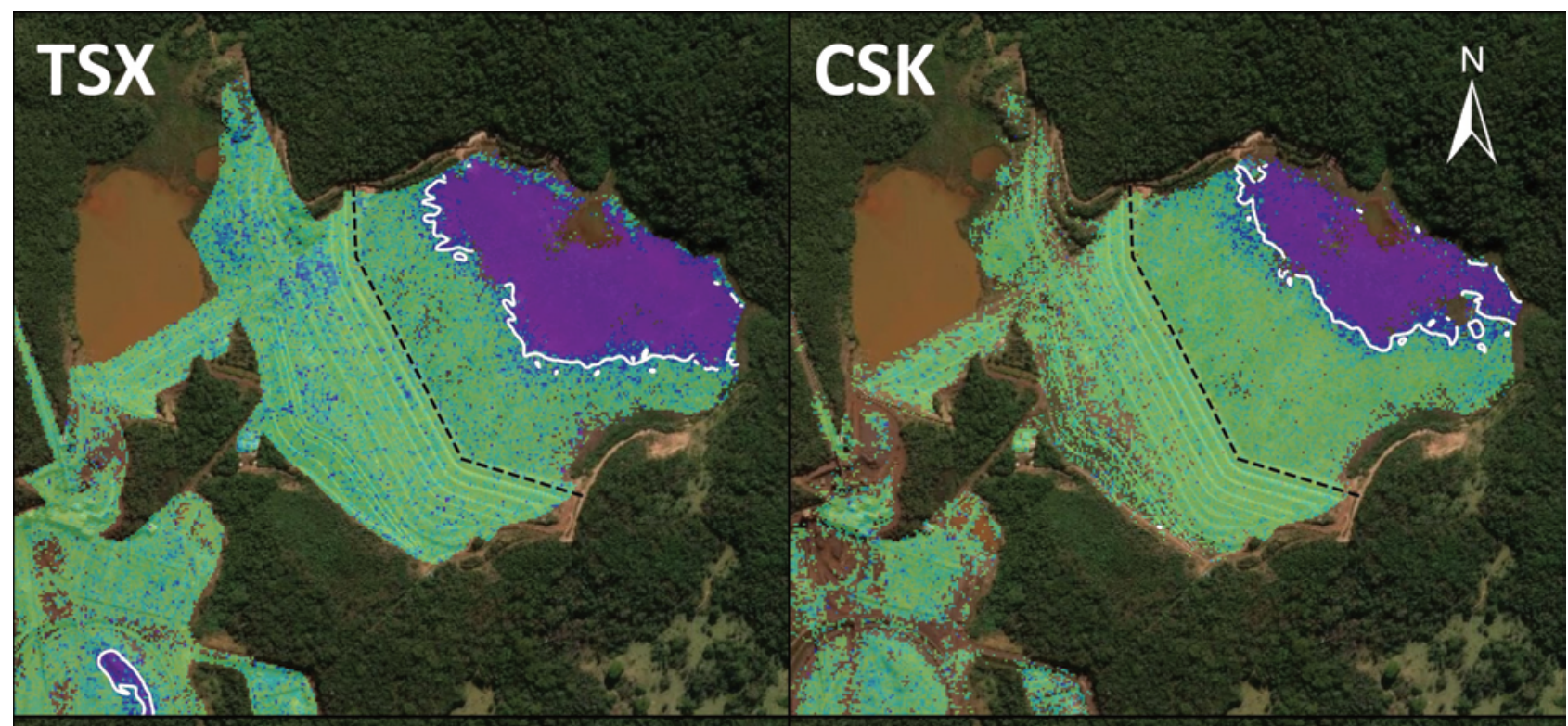

\section{S1 155}
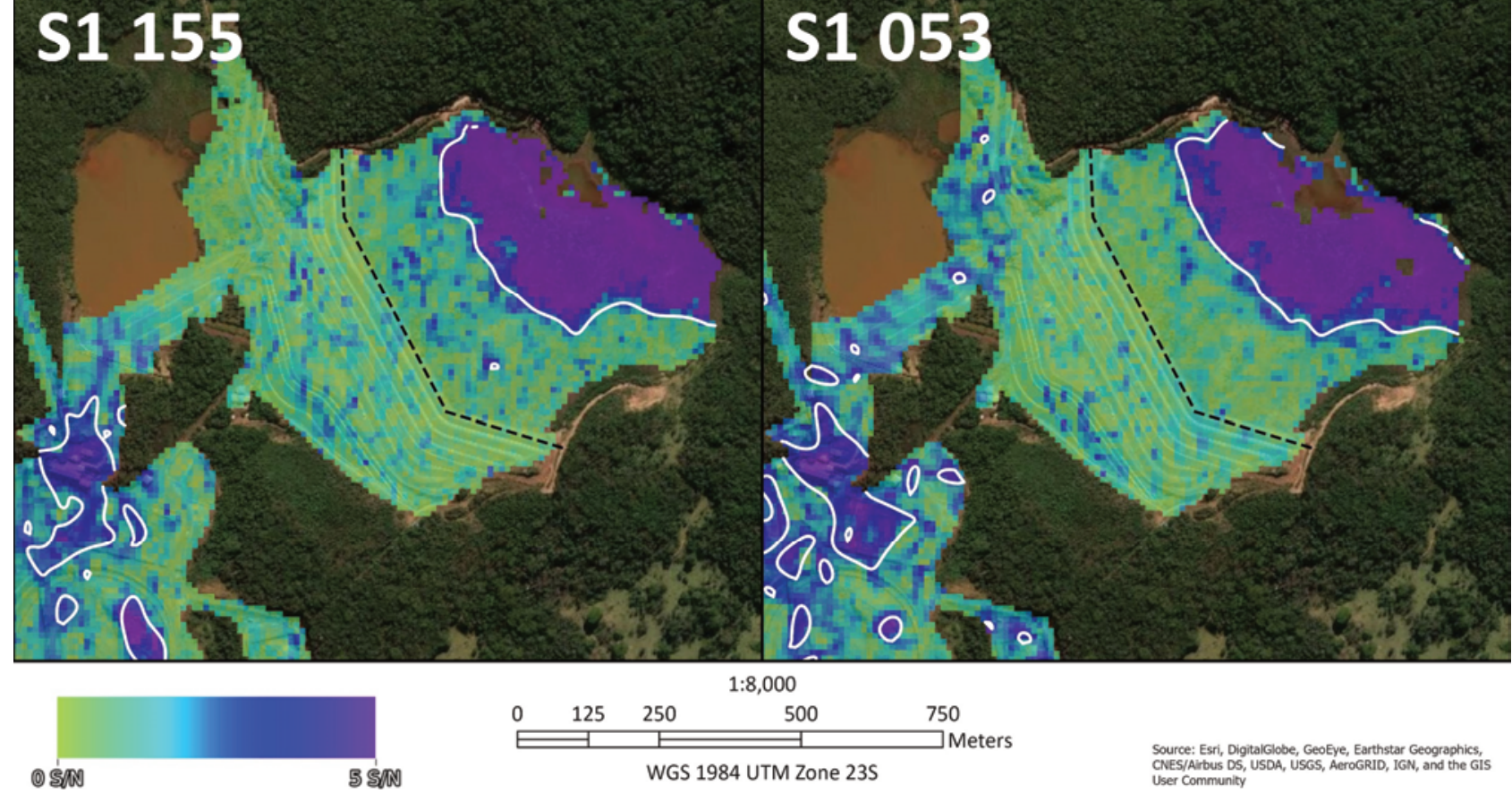

Source: Esri, DigitalGlobe, GeoEye, Earthstar Geographics,
CNES/Airbus DS, USDA, USGS, AeroGRID, IGN, and the GIS CNES/Arbus DS, USD
User Community

Figure 7 Signal-to-noise (SNR) layer of the 1-year rates over Dam I based on ascending TerraSAR-X images (top left), descending CSK images (top right), descending Sentinel-1 (track 053) images (lower right), and descending Sentinel-1 (track 155) images (lower left). Contour lines surrounding areas of greater than 3.0 SNR are in white and the images are scaled between 0 and 5-sigma. The background is the pre-failure optical Esri basemap. The black dashed line denotes the location of the top of the dam

\subsection{Time series}

In all four stacks, significant displacement is detected in the tailings material behind the dam. For the year prior to the collapse, the displacement in the tailings is located primarily in the back half of the tailings, with all four datasets having relatively good agreement, 3-sigma contours within $20 \mathrm{~m}$, regarding the location of the edge of the significant displacement region. This displacement of the tailings shows relatively little internal spatial structure. Figure 6 shows that over the last four years, consolidation in the tailings extended to the top of the dam, with the front of the tailings exhibiting slower rates of consolidation, 2-5 cm p.a., than the back. 
No significant displacement, at the 3-sigma level, is detected on the dam face in any of the one year datasets. In each of the datasets, there are some small features that by eye look potentially of interest, including displacement towards the satellite of $4 \mathrm{~cm}$ p.a. around a central drainage channel in the TSX data, and some isolated regions of 2 to $4 \mathrm{~cm}$ p.a. subsidence along the lower dam face in the S1,053 and 155 track data - but none of these features are significant compared to the noise level at the 3-sigma level. These potential areas of interest appear in different locations in all the datasets, leading extra credence to the notion that they may primarily be due to noise within the data. The CSK rates appear to be highly dominated by noise over much of the dam face. The lower half of the dam, in particular, has higher noise levels in all of the datasets, making detections of subtle displacement challenging.

The full four year dataset of the S1 track 155 dataset has a small region on the lower dam face with a 3-sigma subsidence detection with a rate around $2 \mathrm{~cm}$ p.a. The 053 track data only has two sigma detections with similar rates along the lower dam wall, although at different locations than in the track 155 data. Overall, the dam appears to have been relatively stable, with it potentially undergoing a slow, continuous subsidence of a few $\mathrm{cm}$ p.a. for the last four years.

The displacement rates presented in these results have the best signal quality in areas where the surface is free from vegetation and has not been disturbed for long periods. The coverage reflects this as the signal quality is too low over the vegetated areas to produce reliable results. In non-vegetated areas adjacent to Dam I, there are reasonable quality results, including the detection of settlement in active mining areas. The presence of such standing water results in low return signal, low coherence, and thus gaps in the spatial coverage of the InSAR data. Ponding is likely the cause of the incomplete coverage of the back of the tailings in the different datasets. Some differences between the four results can be also noted including the lower resolution of the $\mathrm{S} 1$ results.

Detailed time series have been calculated for each of the approximately 20,000 and 4,000 points over the tailings structure in the high resolution and low resolution datasets, respectively. Figure 8 shows three regions for which time series are displayed. Figure 9 presents the time series of points on an area on the wall of Dam I (Area A) close to where cracks are initially visible in the video of the failure. Figure 10 shows time series from Area $B$, which is representative of the rapidly subsiding back half of the tailings. Finally, Figure 11 shows the time series for Area $C$, located in the front half of the tailings. For each of these figures, the time series of individual measurement points are shown as grey lines while the average of all points within an area is shown as a red line.

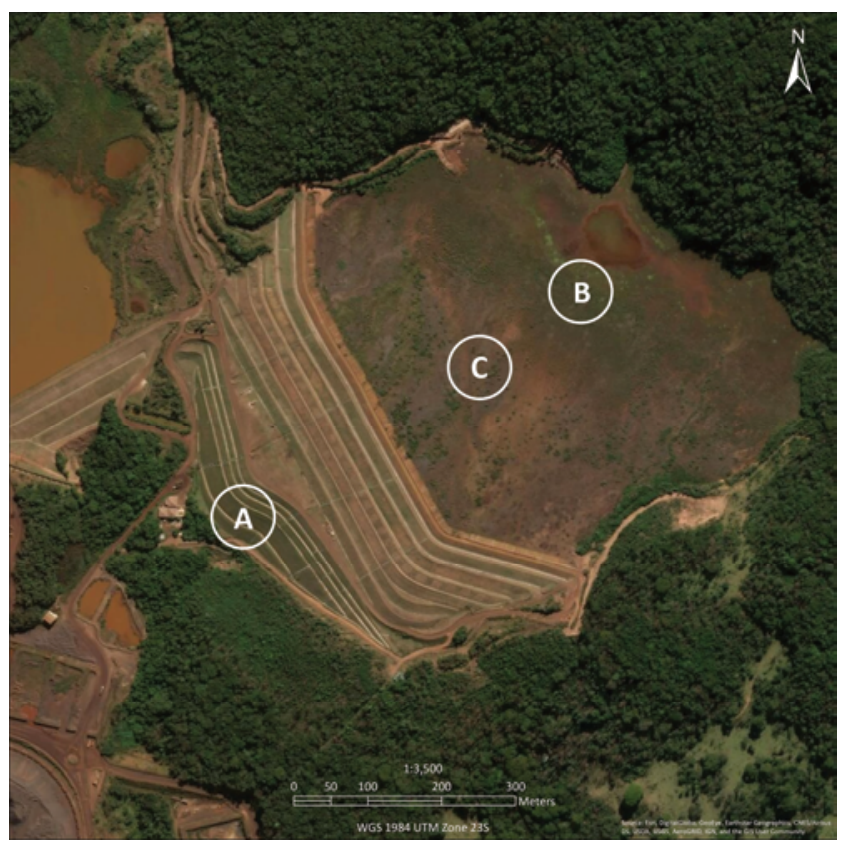

Figure 8 Time series results are shown for measurements corresponding to the annotated areas ' $A$ ', ' $B$ ' and ' $C$ ' in Figures 9-11 respectively 


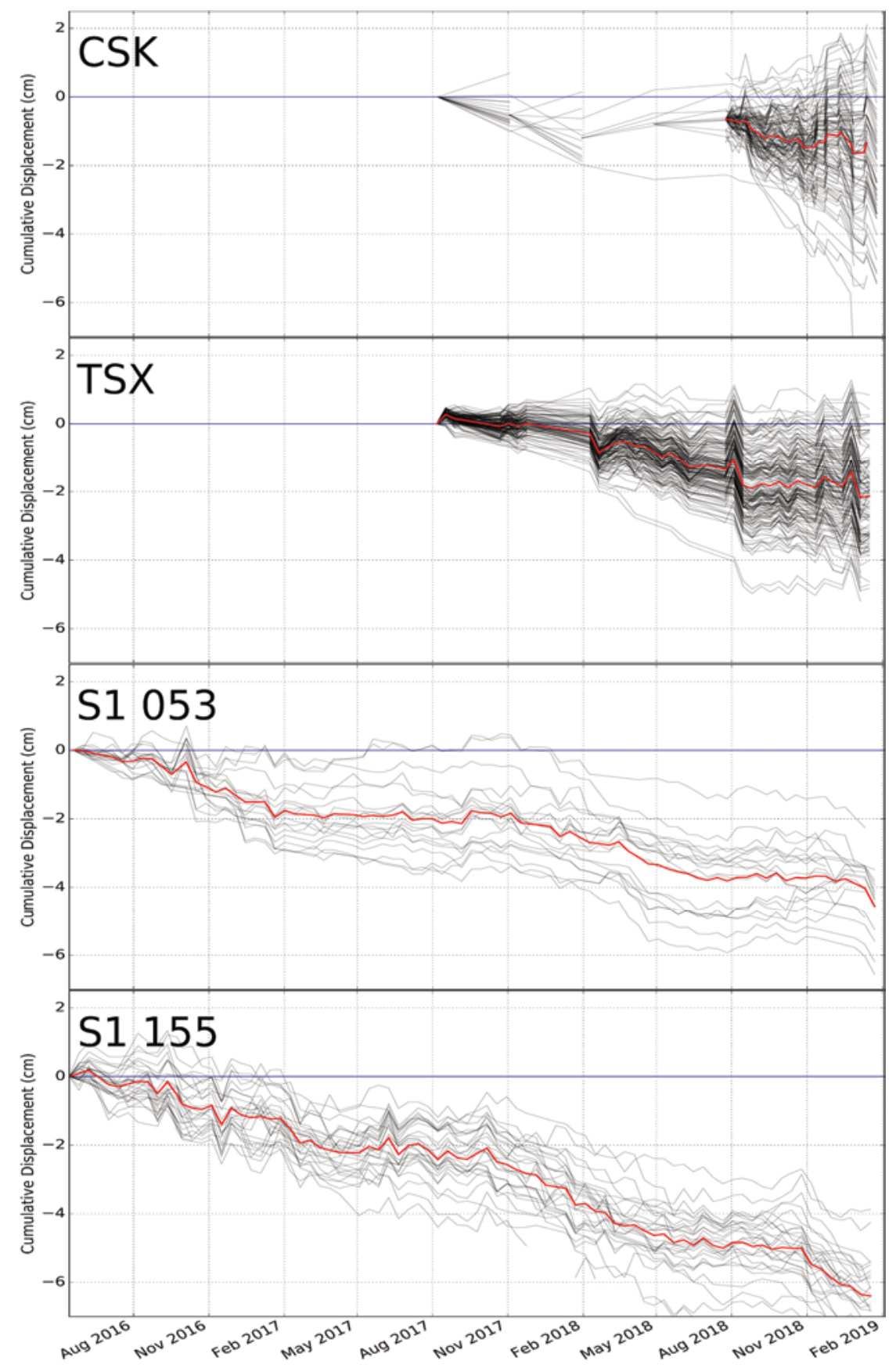

Figure 9 Settlement over time for a sample of points over an area on the lower portion of the dam wall annotated ' $A$ ' in Figure 8 . The black lines show individual points while the red line shows the average of all points in the area 


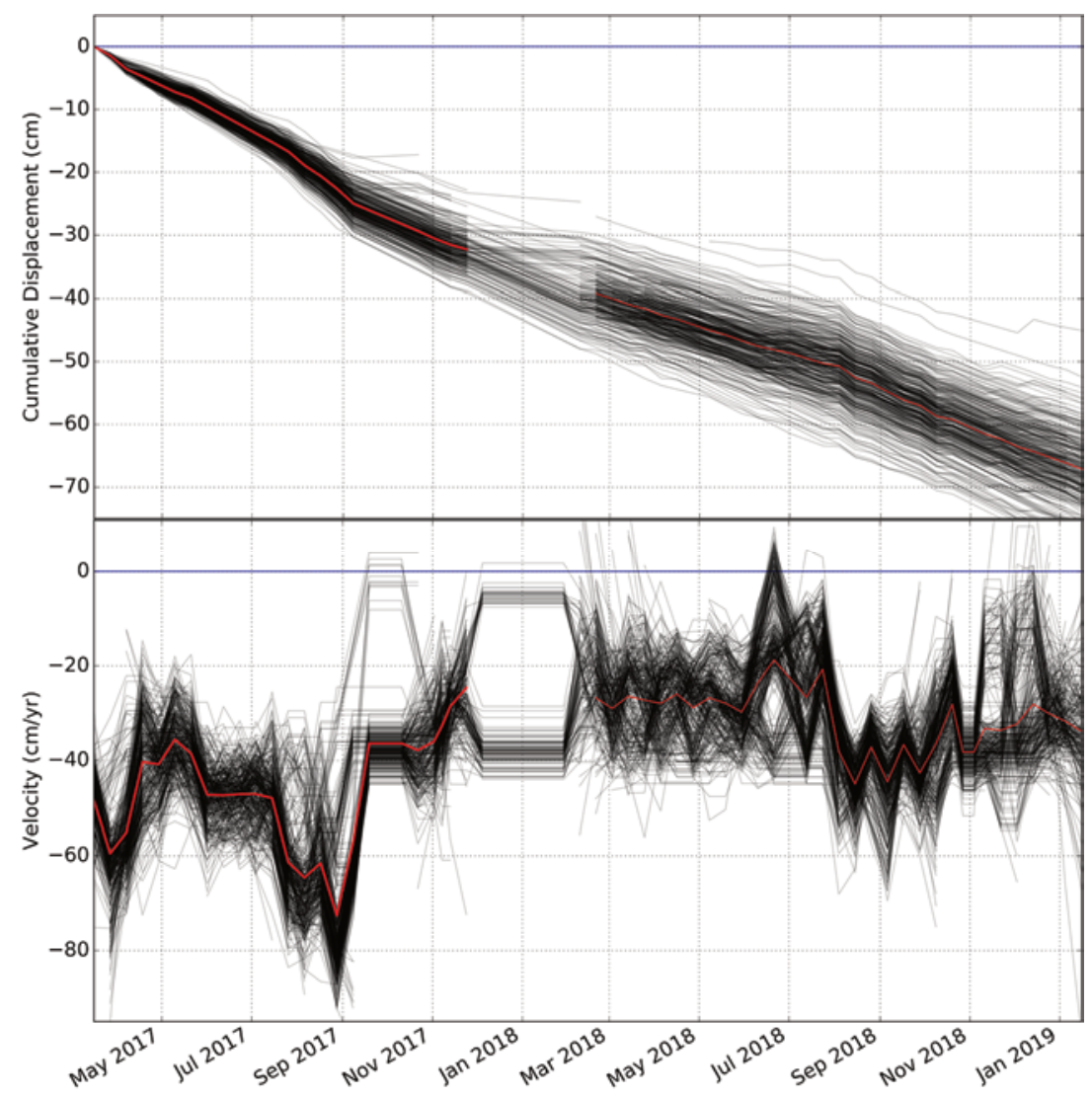

Figure 10 Settlement over time (top) for a sample of points from the TerraSAR-X results over an area towards the back of the tailings material annotated ' $B$ ' in Figure 8 . The corresponding subsidence velocities are given for each time period in the bottom plot. The black lines show individual points while the red line shows the average of all points in the area

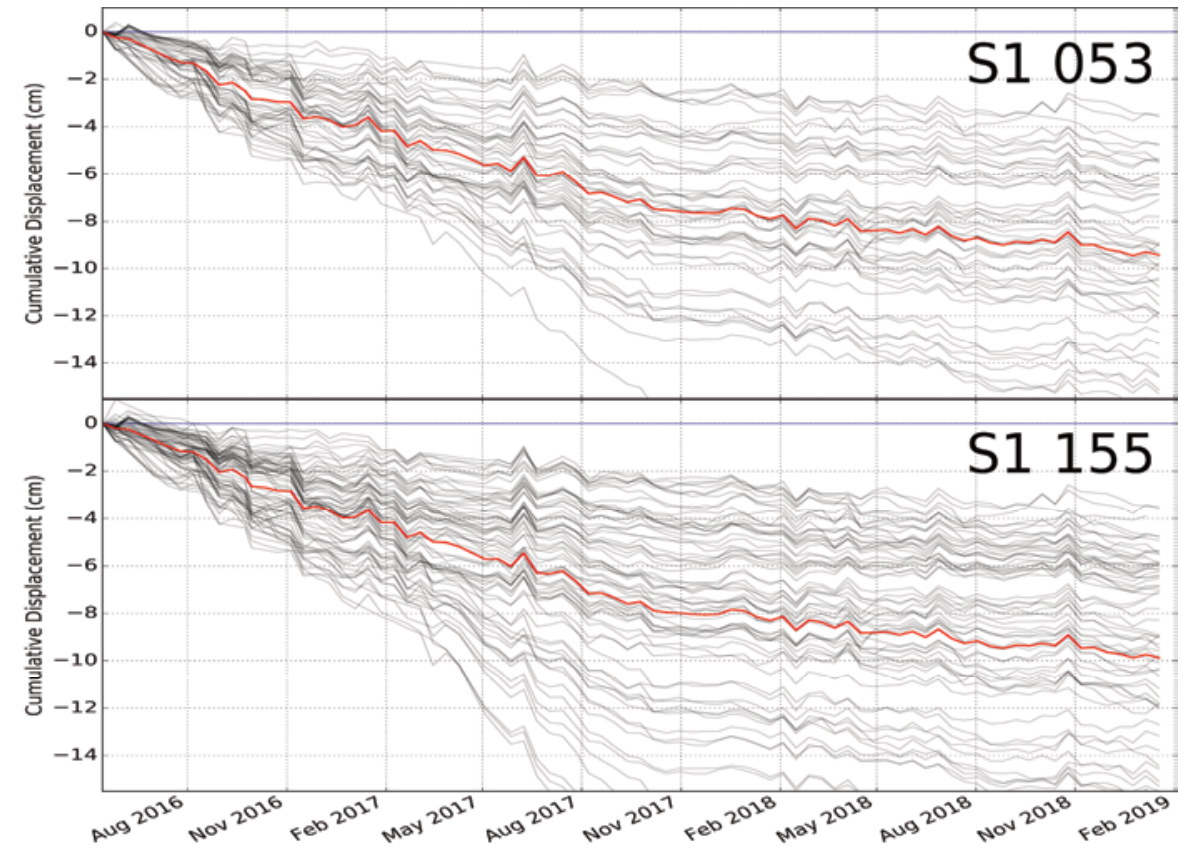

Figure 11 Settlement over time for a sample of points from both Sentinel-1 results over an area within the tailings material annotated ' $C$ ' in Figure 8. The black lines show individual points while the red line shows the average of all points in the area. Both results show a general deceleration of the material which is distinct from the trends shown by measurements further back into the material 
For Area A, all four sensors show relatively steady subsidence of approximately $2 \mathrm{~cm}$ p.a. going back to the beginning of the datasets. Agreement in the magnitude of the displacement measured by ascending and descending datasets would be expected for relatively vertical displacement. There is substantial variation among the different points averaged together within Area A, reflective of the generally high noise level over the lower dam face and resulting in the lack of 3-sigma detections on the dam using only the last year of the data. There is no sign of acceleration immediately prior to the collapse of the dam that is significantly different from the behaviour of the dam in prior years. No warning could have been uniquely given prior to the collapse of the dam based upon this data. There appears to be a subtle seasonal trend, with slightly higher displacement rates in the wetter November-April time period, but the noise level of the data makes any such determination of seasonality quite difficult.

$3 \mathrm{VG}$ has developed an acceleration detection tool that calculates the rate of acceleration within portions of a time series and quantifies the significance of that acceleration. To fully test whether there were any significant acceleration signals prior to the collapse, $3 \mathrm{vG}$ ran this tool on all four stacks. No significant accelerations at the 2-sigma level were detected on the dam wall within the two months prior to the dam failure. Only a few select areas in the back of the tailings showed evidence for significant acceleration. As before, active InSAR monitoring of the dam would not have provided actionable warnings prior to the collapse of the dam.

A significant feature is the settlement of the material inside of the impoundment. Figure 10 shows plots of the measured consolidation and corresponding consolidation velocity of some points close to the fastest areas of settlement. These show that there were periods of acceleration and deceleration prior to the collapse. Rainfall records have not been compared with these results, although the pond area, which is visible in the SAR imagery, does not significantly change in size.

Figure 11 shows a time series from an area near the top of the dam, but still within the tailings, revealing how the rate of subsidence in this area has significantly reduced over time. The edge of the consolidation in the tailings has clearly receded away from the dam wall.

\subsection{Comparison to prior investigations}

Our finding that there were no detectable precursor warnings detectable with InSAR is consistent with the findings of the official expert panel report on the technical causes of the failure of the dam (Robertson et al. 2019). They found that there were 'no apparent signs of distress prior to failure'. Their InSAR analysis found that deformations along the dam face were less than $36 \mathrm{~mm}$ p.a., consistent with slow, long-term settlement of the dam and 'not alone... indicative of a precursor to failure'. From our full S1 datasets, we also found that the dam has been undergoing steady, $2 \mathrm{~cm}$ p.a. displacement for the last four years. The official report found some correlation between subsidence and the wet season over the site.

The results presented here do, however, extend the findings of the official report in a few aspects. The InSAR results in the official report do not cover the back portion of the tailings, whereas Figures 4-7 present rates over this back portion of the tailings. Because of this greater coverage, we find rates exceeding $30 \mathrm{~cm}$ p.a. in the tailings, while the official report only indicates rates up to $14 \mathrm{~cm}$ p.a. Figures 9-11 also show the time series from the S1 data extending back to 2015, while the report only gives time series starting at the beginning of 2018. As such, Figures 9-11 do a much better job capturing the annual, seasonal behaviour of the displacement compared to the official report, which only displayed one year of data.

Other studies (e.g. Tessari et al. 2019) have suggested that precursor accelerations are present in the data. Based on the analysis of this report, we suggest that such trends may not be consistent between different datasets and may not be highly significant compared to the level of the noise and historic trends on the dam. As such, these potential precursors, if identified as part of an InSAR monitoring program, would need to be considered alongside additional site information in order to provide actionable intelligence to dam operators. 


\section{Conclusion}

This study has evaluated four sets of independent InSAR results over the Brumadinho Dam I covering the time period preceding the dam's collapse. The processing chain generated quantitative estimates of the uncertainty on the measurements and these have been used to evaluate the statistical significance of the measured signals. With this approach, no displacement is detected on any large area of the dam structure at a SNR level of 3.0 or higher in the year before the collapse. A steady subsidence of approximately $2 \mathrm{~cm}$ p.a. is detected at one location on the lower dam wall in one of the S1 datasets, but no accelerations are detected on the dam face at the 2-sigma level in any dataset in the two months before the collapse of the dam. This evaluation has been made without any specific geotechnical knowledge of the site, using only the information provided by the InSAR technique. Significant displacement is detected in the back of the tailing material with settlement exceeding $30 \mathrm{~cm}$ p.a. Without the benefit of hindsight, an operational InSAR monitoring program of this dam would not have produced an actionable warning regarding its imminent collapse based on the noise level of the available InSAR data. There are, however, numerous other failures in other mining sites around the world that had easily detectable InSAR precursor signals.

\section{Acknowledgement}

ASF DAAC 2019, contains modified Copernicus Sentinel data 2015-2019, processed by ESA.

\section{References}

3v Geomatics Inc. 2013, RADARSAT-2 Structural Health Monitoring (R2SHM) - Bridge Target Analysis - Milestone 7b, Technical report, 3v Geomatics Inc.

European Space Agency Earth Observation Portal, 2002a, European Space Agency Earth Observation Portal, Paris, viewed 20 October 2019, https://earth.esa.int/web/eoportal/satellite-missions/t/terrasar-x

European Space Agency Earth Observation Portal, 2002b, European Space Agency Earth Observation Portal, Paris, viewed 20 October 2019, https://directory.eoportal.org/web/eoportal/satellite-missions/c-missions/cosmo-skymed

Rabus, B, Werner, C, Wegmueller, U \& McCardle, A 2004, 'Interferometric point target analysis of RADARSAT-1 data for deformation monitoring at the Belridge/Lost Hills oil fields', Proceedings of the Geoscience and Remote Sensing Symposium 2004 (IGARSS'04), vol. 4, Institute of Electrical and Electronics Engineers, New Jersey, pp. 2611-2613.

Robertson, PK, de Melo, L, Williams, D \& Wilson, GW 2019, Report of the Expert Panel on the Technical Causes of the Failure of Feijão Dam I, http://www.b1technicalinvestigation.com

Taylor, K, Ghuman, P \& McCardle, A 2016, 'Operational mine monitoring with InSAR', Proceedings of the First Asia Pacific Slope Stability in Mining Conference 2016, Australian Centre for Geomechanics, Perth, pp. 695-706.

Tessari, G, Stegmaier, P \& Pasquali, P 2019, 'Searching for precursors of the Córrego do Feijão dam collapse in Brumadinho using advanced satellite InSAR', 6th International Seminar on Tailings Management 2019, chapter 5, viewed 20 October 2019, http://www.gecaminpublications.com/tailings-2019

Thomas, A, Edwards, SJ, Engels, J, McCormack, H, Hopkins, V \& Holley, R 2019, 'Earth observation data and satellite InSAR for the remote monitoring of tailings storage facilities: a case study of Cadia Mine, Australia', Proceedings of the 22nd International Conference on Paste, Thickened and Filtered Tailings, Australian Centre for Geomechanics, Perth, pp. 183-195.

Vale S.A. 2019a, 107 people receive the $R \$ 100,000.00$ donation, press release, viewed 20 October 2019, http://www.vale.com/brasil/EN/aboutvale/news/Pages/107-people-receive-the-100000-donation.aspx

Vale S.A. 2019b, Clarifications regarding Dam I of the Córrego do Feijão Mine, press release, viewed 20 October 2019, http://www.vale.com/brasil/EN/aboutvale/news/Pages/Clarifications-regarding-Dam-I-of-the-Corrego-do-Feijao-Mine.aspx

Williams, C, Ross, B, Zebker, M, Gaida, M, Morkeh, J \& Robotham, ME 2019, 'Assessment of historic InSAR monitoring data prior to the Manefay Slide at the Bingham Canyon Mine using the latest analytical techniques', Proceedings of the 53rd U.S. Rock Mechanics/Geomechanics Symposium, American Rock Mechanics Association, Alexandria, ARMA-2019-2881. 